\title{
Antecedents of everyday positive emotions: An experience sampling analysis
}

\author{
Thomas Goetz - Anne C. Frenzel - Heidrun Stoeger • \\ Nathan C. Hall
}

\begin{abstract}
The focus of this study is on everyday positive emotions and their relations to critical appraisal antecedents. Following from classical appraisal theory and Pekrun's (2006) control-value theory of achievement emotions, two research questions were addressed, namely whether cognitive appraisals of control and value were related to discrete positive emotions in everyday situations and whether control and value antecedents interact in predicting these emotions. We further investigated whether control/ value and positive emotion relations changed as a function of situational factors (achievement vs. non-achievement settings). 50 university freshmen ( $78 \%$ female) were assessed by use of the experience sampling method for a period of 1 week, with intraindividual analyses conducted using a multilevel, idiographic approach. Consistent with our hypotheses, the emotions of enjoyment, pride, and contentment were positively related to control and value appraisals. Further, control and value interacted to predict
\end{abstract}

T. Goetz (ه)

University of Konstanz, Universitaetsstr. 10, 78457 Constance, Germany

e mail: thomas.goetz@uni konstanz.de

T. Goetz

Thurgau University of Teacher Education, Thurgau, Switzerland

A. C. Frenzel

University of Munich, Munich, Germany

H. Stoeger

University of Regensburg, Regensburg, Germany

N. C. Hall

University of Maryland, College Park, MD, USA these positive emotions. The strength of appraisal/positive emotion relations was equivalent across achievement vs. non-achievement settings. Implications for future research are discussed.

Keywords Emotion - Appraisal - Control - Value Enjoyment · Pride $\cdot$ Contentment $\cdot$ Experience sampling method

\section{Introduction}

Positive emotion experiences are an important topic of investigation for multiple reasons. According to Pekrun et al. (2002b), positive emotions "help to envision goals and challenges, open the mind to thoughts and problemsolving, protect health by fostering resiliency, create attachments to significant others, lay the groundwork for individual self-regulation, and guide the behaviour of groups, social systems, and nations" (p. 149). In the same vein, Fredrickson (2001) states that "positive emotions are worth cultivating, not just as end states in themselves but also as a means to achieving psychological growth and improved well-being over time" (p. 218; for positive emotions in the context of "Positive Psychology" see also Seligman and Csikszentmihalyi 2000). Given the clear relevance of positive emotions, the antecedents of these emotions represent an important avenue of research. More specifically, it is by examining why one experiences specific positive emotions that ideas can be generated as to how to best foster positive affective experiences.

We focus in the present study on cognitive appraisals as antecedents of emotions. The assumption that our perception of events, rather than events themselves, impact our emotions has a long historical tradition dating back to the 
work of philosophers such as Epictetus, Marcus Aurelius, and Seneca. ${ }^{1}$ In the context of psychological theories, the idea that cognitive appraisals mediate the impact of life events on emotional experiences has remained a prominent topic of discourse since the 1900s (Lazarus 1991; Stumpf 1899). Accordingly, psychological research efforts have also consistently underscored the importance of individuals' evaluations of events, actions, or objects as primary eliciting factors with respect to emotional experiences (Clore 1994; Roseman and Smith 2001)

Modern emotion theories have explored a number of cognitive appraisals as potential antecedents of emotions including valence, goal congruency, goal conduciveness, expectedness, controllability, and normative significance (Roseman 2001; Scherer 2001). In addition to studies focusing on specific appraisals as independent emotion antecedents, considerable research conducted in the context of appraisal theories has examined configurations of appraisal constructs as predictors of subsequent emotions (e.g., anger predicted by high perceived aversiveness and high perceived agency of others; see Arnold 1960; Roseman et al. 1990, 1996; Smith and Ellsworth 1985; Tong et al. 2007). However, there exists relatively little empirical evidence to date in support of the interactive effects of specific appraisal combinations in which the prerequisite appraisal constructs are held constant. Thus, intriguing theoretical questions remain concerning the extent to which the combined impact of multiple appraisals on subsequent emotions is indeed more than simply the additive effect of the constituent appraisal constructs. Such questions are also of potential practical importance concerning the development of effective and efficient interventions programs for fostering positive emotions focusing on either individual appraisal variables (e.g., perceived control), or alternatively, optimal combinations of appraisal constructs (e.g., perceptions of control and value).

Further, these research questions are of relevance with respect to efforts to improve teaching strategies and develop interventions that encourage positive emotions in addressing the potential moderating influence of situational characteristics on the strength of appraisal/emotion relations (e.g., the individual vs. interpersonal, or achievement vs. leisure-oriented nature of a given situation). Whereas classical appraisal theory does not contain formulated assumptions with respect to situational moderators of appraisal/emotion relations, the potentially domain-specific nature of such relations is highlighted in Pekrun's (2006) control-value theory of emotions in which the effects of specific appraisal antecedents on emotions as experienced exclusively in the achievement domain are hypothesized.

\footnotetext{
$\overline{1}$ E.g., "Men are disturbed not by the things which happen, but by their opinions about the things" (Epictetus; Long 1991, p. 14).
}

However, although the domain-specific nature of Pekrun's model may afford some degree of generalization concerning the proposed relations to non-achievement settings, the extent to which appraisal/emotion relations are in fact moderated by situational characteristics has yet to be theoretically or empirically addressed.

Beyond theoretical assumptions, an additional unexplored area of research involving appraisal/emotion relations pertains to commonly mentioned concerns surrounding the ecological validity of existing research methods. More specifically, recent studies have primarily employed experimental approaches, hypothetical vignettes, trait assessments, as well as retrospective interviews methods characterized by a trade-off favoring experimental control at the expense of real-world relevance (e.g., Tong et al. 2007). In an effort to complement such previous findings, recent field studies have provided encouraging results concerning the relations between appraisal and emotions through the use of real-time assessments (e.g., experience sampling methods) that provide a more naturalistic, in vivo assessment of individuals' perceptions and experiences in real-world settings (e.g., Nezlek et al. 2008).

In sum, positive emotional experiences and their causal antecedents, as explored in the context of appraisal theory, represent an important and burgeoning area of psychosocial research. Empirical findings based on appraisal theory have evaluated a number of appraisal constructs as possible antecedents of positive emotions. However, despite the considerable relevance of such research for the development of interventions aimed at promoting positive emotions, specific knowledge as to the interactive effects of appraisal combinations, controlling for their constituent main effects, as well as the degree to which appraisal/ emotion relations differ as a function of situational factors, is presently lacking. Moreover, few empirical studies have to date employed non-retrospective methods of assessment providing a high degree of ecological validity in empirical investigations of appraisal/emotion relations (e.g., experience sampling method).

The focus of the present study was to contribute to ongoing research concerning the relations between positive emotions and appraisal antecedents so as to optimally inform the development of effective interventions aimed at fostering emotional well-being in real-world settings. Two critical emotion antecedents commonly identified in appraisal theories were investigated, namely perceptions of control and value (see Pekrun 2006), in terms of their individual as well as combined effects on three positive emotional experiences including enjoyment, pride, and contentment. In an effort to further contribute to research in this domain, these relations were explored through the use of the experience sampling method (Hektner et al. 2007) thus allowing not only for highly ecological, real-life 
assessments of the appraisal and emotion constructs, but also an evaluation of the potential moderating impact of the specific characteristics of a given situation (achievement vs. non-achievement settings).

Control and value antecedents of emotions

In this study, we investigated two dimensions of cognitive appraisals assumed to each play a crucial role in eliciting positive emotional experiences, namely perceptions of control and value. These dimensions are commonly cited in several appraisal models (Scherer et al. 2001) and are specifically highlighted as core antecedents of achievement-related emotions (see Pekrun 2006).

\section{Perceived control}

This dimension generally refers to beliefs about the extent to which one can predict and personally influence life events (Bandura 1989; Heckhausen 1977; Skinner 1985, 1996). In empirical research on perceptions of control, three major lines of investigation have explored the relation between subjective control and emotional experiences, namely locus of control (Lefcourt 1983; Levenson 1973; Rotter 1966), self-efficacy beliefs (Bandura 1977, 1989, 1997), and attribution theory (Weiner 1985).

According to the locus of control model, individuals with an internal locus tend to believe that situational outcomes can be controlled by their own behavior, whereas those with an external locus generally believe that outcomes are impacted by factors beyond their control. Empirical evidence suggests that an internal locus is positively related to positive emotions, whereas an external locus is negatively related to positive emotions (e.g., Alloy and Clements 1992; Henson and Chang 1998; Hoffart and Martisen 1990). These findings thus suggest that greater perceived personal control should correspond with high levels of positive emotions.

The second line of investigation on control/emotion relations involves research on self-efficacy (Bandura 1977, 1989, 1997) defined as "people's beliefs about their capabilities to exercise control over events that affect their lives" (Bandura 1989, p. 1175). Empirical research in this area suggests that high levels of perceived efficacy regarding one's response to potentially threatening events also correspond to more positive emotional experiences (see Bandura 1997).

Finally, the third line of research on control/emotion relations is based on Weiner's attribution theory concerning the "perceived causes of success and failures" (causal attributions; Weiner 1985, p. 549). In this model, three dimensions are identified along which attributions can be classified, one of which is perceived controllability (influenced by vs. independent of one's behavior). Various discrete, attribution-dependent emotions are postulated in Weiner's model, with each emotion predicted primarily by outcome valence and one causal dimension (e.g., success + internal attribution $\rightarrow$ pride). In sum, theoretical assumptions and empirical evidence suggests that subjective personal control is related to greater positive affect.

\section{Perceived value}

Appraisal theories incorporate perceptions of value to account for the relation between goal conduciveness and emotional experiences (Scherer 1984). Goal conduciveness refers specifically to the personal relevance of an outcome or an activity (Scherer 1984), and is assessed using questions such as "How relevant is this event for me?" (Scherer 2001, p. 94). From a theoretical perspective, high levels of personal relevance should coincide with a greater intensity of positive emotional experiences. For example, one should experience greater enjoyment following a positive event of high as opposed to low personal relevance. There exists empirical evidence of positive relationships between perceived value and positive emotional experiences. Studies by Frenzel, Pekrun, and Goetz (2007), Goetz (2004), and Goetz, Pekrun, Hall, and Haag (2006) with students from grades 510 found positive relations between perceived value and positive emotions (enjoyment, pride) assessed in a trait-like manner in an achievement setting.

\section{Control and value interactions}

As outlined above, both perceptions of control and value are assumed to have beneficial independent effects on positive emotional experiences. However, it is also plausible that optimal levels of positive emotional experiences may result from the interactive or combined effects of control and value appraisals. As outlined below, this potential predictive utility of appraisal combinations concerning positive emotional experiences is underscored by the assumptions of both classical appraisal theory as well as Pekrun's (2006) control-value model of emotion in achievement settings.

\section{Classical appraisal theory}

Appraisal theorists have long asserted that specific emotional experiences depend on combinations of discrete appraisals (see Arnold 1960 for the first modern attempt to specify appraisal/emotion relations). This assumption of unique relations between appraisal configurations and emotions has also received empirical support in studies based on the classical appraisal paradigm (e.g., appraisal 
configuration for fear: perceived aversiveness [-], goal conduciveness $[-]$, perceived control $[-]$, perceived agency: circumstances [+]; see Roseman et al. 1990, 1996; Smith and Ellsworth 1985).

Despite the intriguing nature of these results, the contribution of these findings to our understanding of the added predictive validity of appraisal configurations is significantly limited due to unfortunate exclusion of the constituent appraisal main effects as covariates. In other words, when evaluating the effects of appraisal interactions (e.g., $\mathrm{A} \times \mathrm{B}$ ), the independent main effects of these appraisal constructs (A, B) were not simultaneously accounted for (see below for Tong et al. 2007 as an exception). Thus, the question arises as to whether the impact of an appraisal configuration (e.g., $\mathrm{A} \times \mathrm{B}$ ) on an emotional experience is stronger than simply the additive effect of the constituent appraisal constructs $(\mathrm{A}+\mathrm{B})$.

\section{Pekrun's (2006) control-value theory of achievement emotions}

Following from more generalized, classical appraisal approaches is Pekrun's control-value theory in which both distal (e.g., parental support) and proximal antecedents of achievement emotions (e.g., appraisals), namely emotions as experienced in situations involving learning and achievement, are explicitly addressed. With respect to specific appraisal constructs, subjective control and value are identified in Pekrun's model as of particular relevance to achievement emotions. Further, Pekrun's theory is consistent with the expectancy-value tradition of motivation research (e.g., Atkinson 1964) in that "expectancy and value are assumed to combine in multiplicative ways, implying that both expectancy and value are necessary for a prospective emotion to be instigated" (Pekrun 2006, p. 320). More generally, the model hypothesizes that "for most academic emotions, both control and value are necessary antecedents" (Pekrun et al. 2002a, p. 101).

Several recent empirical studies have evaluated, and provided evidence in support of, the theoretical tenets of Pekrun's control-value theory concerning the proposed relations between achievement-related appraisals and emotions. In these studies, significant positive relations have consistently been observed between both perceptions of control and value on the one hand, and positive emotional experiences on the other, as assessed in situations involving learning activities and achievement outcomes (e.g., Frenzel et al. 2007; Goetz et al. 2006, 2008). However, despite the assumed multiplicative impact of control and value appraisals on emotions, there exists to date no single study in which the added benefit of such interactions for positive emotional experiences in achievement settings are evaluated controlling for the constituent main effects.
Control/value and emotion relations as moderated by domain

In Pekrun's (2006) control-value theory, appraisals of control and value are central to the arousal of achievementrelated emotions. In this respect, this model is consistent with classical assumptions of appraisal theory (see Scherer et al. 2001). However, while Pekrun's (2006) focus is on emotions tied directly to activities or outcomes involving learning and achievement, appraisal theory is more general in nature. Thus, with respect to our research questions concerning the independent and combined effects of specific appraisals on emotion experiences, the potential moderating effect of the achievement-oriented nature of a given situation on the observed relations between control/ value and emotion was explicitly addressed.

\section{Appraisal and emotion relations in everyday situations}

Two studies to date have explored the relations between appraisals and emotions as assessed in real-life situations (Nezlek et al. 2008; Tong et al. $2007^{2}$ ), motivated by concerns surrounding the ecological validity of impressive yet laboratory-based findings of earlier research. With respect to previous experimental findings (e.g., Alloy and Abramson 1979), such concerns pertained mainly to the highly artificial and questionable real-world relevance of the laboratory settings (see Lazarus 1995; Tong et al. 2007), as well as the potentially restricted intensity of the emotions evoked as compared to more naturally occurring emotional experiences. With respect to the use of hypothetical vignettes (e.g., Smith et al. 1993), stereotypic perceptions of how one should react could pose potential response biases. Further, trait assessments (e.g., Goetz et al. 2006) may reflect overall cognitive schemas about cognitions and emotions rather than actual experiences, and retrospective interviews can be tainted by recall biases (e.g., Roseman et al. 1996).

In Tong et al. (2007), Ecological Momentary Assessment was employed in which police officers from Singapore $(N=118$; ages 1950$)$ reported their current appraisals and emotions "online" at 30-min intervals throughout an entire workday. Each participant provided, on average, 11 observations (range $=1420$ ) concerning 12 appraisal constructs (e.g., control: "How much control do you have over the event?"), five negative emotions, and a single positive emotion (happiness). Results showed this positive emotion to have positive relations with 8 of the 12 appraisals assessed. Competitive evaluations of the eight

\footnotetext{
2 An additional brief report by Tong et al. (2005) is not presented due to including a subset of variables subsequently evaluated in Tong et al. (2007)
} 
appraisal constructs showed happiness to be primarily predicted by high levels of pleasantness, goal-conduciveness, as well as certainty (marginally). Finally, analyses of two- and three-way interactions between these three appraisals on happiness also revealed a significant threeway interaction term indicating that specific configurations of appraisal constructs do indeed play an important role as antecedents of emotions.

In a second experience sampling study conducted by Nezlek et al. (2008), university students $(N=36$; ages 19 33 ) responded to multiple appraisal and emotion measures concerning their experiences just prior to the response signal (nine signals per day for 2 weeks). Each participant provided an average of 104 assessments concerning six appraisals (e.g., other-blame, self-blame, threat) and six emotions including two positive emotion constructs (joy, love). Both positive emotions showed significant positive relations with positive interpersonal encounters and experiences of success, whereas negative relations were observed between positive emotions and threat appraisals, other-directed blame, and self-directed blame, as well as between joy and perceptions of loss.

In sum, these studies found clear relations between appraisals and positive emotions in the context of everyday experiences. The Tong et al. (2007) study also indicates that configurations of appraisals may contribute to the prediction of emotional experiences over and above the effects of individual appraisals. Further, both studies extend significantly upon previous research on appraisal/emotion relations through the utilization of real-life assessments assumed to have significantly greater ecological validity than laboratory-based methodological approaches (e.g., vignettes, retrospective recall). Despite the utilization of in vivo methods, however, the findings observed warrant further investigation concerning the independent and interactive effects of unexplored yet critical appraisal constructs, namely perceptions of control and value, as well as the moderating influence of situational characteristics (e.g., achievement vs. non-achievement settings).

The present study

Our study follows from both classical and recent appraisal theories of emotion (e.g., Pekrun 2006; Roseman et al. 1990) as well as ongoing research on appraisals/emotion relations as assessed in everyday life (Nezlek et al. 2008; Tong et al. 2007) in exploring critical cognitive appraisal antecedents of positive emotional experiences. The present study extends upon previous research employing real-life assessments by focusing specifically on the appraisal constructs of control and value, and analyzing their independent as well as interactive effects on positive emotions.
Further, the current study investigates the moderating impact of situational factors in evaluating potentially differential patterns of appraisal/emotion relations in situations related to learning and achievement as opposed to non-achievement settings.

Hypothesis 1 The first aim of our study was to investigate whether appraisals of control and value are related to positive emotions in everyday situations. Consistent with previous studies showing clear relations between discrete emotions and their control/value antecedents (e.g., Frenzel et al. 2007a, b; Goetz et al. 2006, 2008; Roseman et al. 1996; Scherer 1988; Tong et al. 2007), we hypothesized that control and value appraisals should also elicit positive emotions in everyday life. More specifically, when assessed with respect to everyday activities, perceived control should correspond positively with the positive emotions of enjoyment, pride, and contentment. Further, higher levels of perceived value should also coincide with greater positive emotions (Goetz et al. 2006).

Hypothesis 2 In addition to analyzing the independent effects of appraisals on positive emotions, the present study investigated the interactive effects of perceived control and value on positive emotional experiences. In line with Pekrun's $(2000,2006)$ control-value theory, we hypothesized that control and value should combine multiplicatively (rather than just additively) to predict the intensity of positive emotional experiences in a given everyday situation.

For each of the two hypotheses, the potential moderating effect of being in an achievement as opposed to nonachievement situation on control/value and positive emotion relations was evaluated. More specifically, following from both classical and Pekrun's (2006) appraisal theories of emotion, the learning and/or achievement-oriented nature of a given setting was investigated as an additional variable further moderating both the independent effects (Hypothesis 1) and interactive effects (Hypothesis 2) of control and value appraisals on positive emotion experiences.

\section{Method}

Sample and data collection

The sample consisted of 50 German university freshmen (78\% female) recruited from an introductory psychology class for a voluntary research study. The present sample was restricted only with respect to sample size (maximum 50), and was not selective in including only participants having satisfied a predetermined compliance threshold. 
Their mean age was 22.43 years (range: [18.58; 29.58]; $\mathrm{SD}=3.02$ ). Data collection took place by use of the experience sampling method (Csikszentmihalyi and Larson 1987; Hektner et al. 2007). Participants were provided with personal digital assistants (PDAs) as signaling devices and 42 hard copy state questionnaires (daily report forms; $5.5 \times 8.5$-inch sheet) by trained testing personnel and were collected one week later. Participants were instructed to have the signaler, questionnaires, and a pencil constantly with them for the entire week. No contact with participants occurred during the ESM phase of the study.

Consistent with the aim of obtaining representative data on individuals' experiences throughout the entire day, our assessment was based on a time randomizing procedure (signal-contingent sampling; see Hektner et al. 2007) in which the number of signals, the earliest and latest possible signal, as well as the minimal time lag were used as default parameters. More specifically, the signalers emitted six audible signals per day. With respect to the time commitment required of participants, the signals were emitted between 9:00 am and 10:00 pm. Within this 13-h time frame, a minimal time lag of $60 \mathrm{~min}$ was imposed between assessments resulting in a theoretically maximal time lag of $9 \mathrm{~h}$ between assessments within a given day. Participants were asked to complete a new questionnaire immediately following each auditory signal. Were this not feasible (e.g., during exams), participants were instructed to complete the questionnaire as soon as possible thereafter. In this case, they were to refer to their current experiences (i.e., a state assessment), and were explicitly informed not to retrospectively describe their experiences when the signal occurred in order to minimize recall biases. The questionnaire first asked participants to describe the context in which they were situated when the signal occurred, followed by questions concerning their cognition appraisals and positive emotions concerning the situation.

This assessment procedure resulted in a maximum of 42 completed state questionnaires for each participant (7 days $\times 6$ signals per day), or 2,100 questionnaires overall (42 questionnaires per person $\times 50$ participants). The final totals included 2,001 complete questionnaires (95.3\%), 25 partially complete questionnaires (1.2\%), and 74 empty questionnaires $(3.5 \%)$ from a total of 31 participants. Of the 2,026 fully or partially completed questionnaires, the average number of questionnaires completed per person was 40.5 (range: [28; 42]; median: 41). Further, the observed time to completion following the signal among participants with fully or partially completed questionnaires was as follows: $1,282(63.3 \%)$ within $1 \mathrm{~min}, 471$ $(23.2 \%)$ between 1 and $5 \mathrm{~min}, 128(6.3 \%)$ between 6 and $15 \mathrm{~min}, 84(4.1 \%)$ between 16 and $30 \mathrm{~min}, 37(1.8 \%)$ between 31 and $60 \mathrm{~min}$, and $24(1.2 \%)$ more than $60 \mathrm{~min}$.
Study measures

\section{Domain}

In order to categorize the context in which individuals were situated when the signal occurred, participants were asked to respond to the following open-ended question: "What are you currently doing?" Responses to this item were categorized as consisting of either (a) activities related to learning and achievement (e.g., studying for an exam, attending class), or (b) other tasks not related to achievement (e.g., watching TV, having lunch). ${ }^{3}$ Based on this categorization, a dummy variable entitled "achievement situation" was created $(0=$ non-achievement, $1=$ achievement $)$. Data on this dichotomous measure was not available for 150 of the 2,100 questionnaires $(7.1 \%)$ as information on the individual's current activity was missing or could not be determined.

\section{Control and value appraisals}

Perceived control was assessed with the item "I have the impression that the situation is under my control" (cf., Burger 1989; Skinner 1985, 1996; for a similar control assessment, see Tong et al. 2007). ${ }^{4}$ The response format consisted of a 5-point Likert scale ranging from 1 (strongly disagree) to 5 (strongly agree). Our assessment of overall value was based on Scherer (2001) and asked participants to rate their agreement on a 5-point scale with the anchors "The current activity is unimportant for me" (1), and "The current activity is important for me" (5).

\footnotetext{
${ }^{3}$ Very few participants' reports (1.8\% of 2,026 fully or partially completed questionnaires) referred to situations that were not learning or achievement related in the classical sense (e.g., studying), but may have been perceived by the individual as achievement oriented in nature (e.g., sports, playing an instrument, playing chess). However, to avoid potential confounds involving the leisure oriented nature of such activities, they were coded as non achievement situations in the present analyses.

${ }^{4}$ In the present study, multiple constructs were assessed using single items (cf., Goetz et al. 2007; Wanous et al. 1997). Although multi item measures are generally preferable for assessing multi faceted constructs, such measures take longer to complete than single item measures and could compromise the assessment of state emotional experiences. More specifically, when participants are asked about state emotions, longer self report measures could confound partici pants' responses by introducing greater reflection time and recall bias. In addition, by taking more time to respond, multi item scales might be in danger of assessing participants' emotions with respect to completing the questionnaire, rather than emotions concerning the activity they are currently engaged in. For these reasons, single item measures were assumed to be more appropriate than multi item measures for use in this study.
} 


\section{Emotions}

We investigated three positive emotions including enjoyment, pride, and contentment; positive emotions that are frequently experienced both within and outside achievement settings (Goetz et al. 2007; Pekrun et al. 2002a; Scherer et al. 2004). Single-item measures were employed for each of the emotions assessed. ${ }^{4}$ Item wordings focused on how participants felt in relation to the specific activity in which they were currently engaged (cf., Clore 1994). In contrast to responses involving more general situations or events, references to one's current activity allow for clearer and more concrete assessments of state emotional experiences. The items were formulated as follows: "The current activity makes me feel happy/proud/content." The response format consisted of a 5-point Likert scale ranging from 1 (strongly disagree) to 5 (strongly agree).

Statistical analyses

\section{Preliminary analyses}

Our data represent a two-level structure, with measures (Level 1; $N=2,100$ ) nested within persons (Level 2; $N=50$ ). In a preliminary analysis, the means, standard deviations, and intercorrelations among study measures were calculated. We focused in this analysis on Level 1 (within-person measures) due to the present study focus on within-person relations (intraindividual analyses, idiographic approach; see Lamiell 1998). Further analyses on the proportions of between- and within-subject variances (intra-class correlations) were conducted via multilevel statistics using the program HLM 6.04 (Hierarchical Linear Modeling; Raudenbush et al. 2007; Raudenbush and Bryk 2002). All variables were standardized prior to performing the multilevel analyses $(M=0, \mathrm{SD}=1$; see Marsh and Rowe 1996).

\section{Main analyses}

With respect to the main analyses, hierarchical linear models (HLM 6.04) were conducted including each emotion assessed as a dependent variable. The independent variables consisted of achievement setting (AS; $0=n o$, $1=$ yes), control (C), and value (V). As the present analyses focused on effects within persons (intraindividual, idiographic approach; see Lamiell 1998), all independent variables were centered on the group mean, that is, for each individual on his or her mean.

All possible interactions between the independent variables were also included in the HLM models $(\mathrm{C} \times \mathrm{V}$, $\mathrm{C} \times \mathrm{AS}, \mathrm{V} \times \mathrm{AS}, \mathrm{C} \times \mathrm{V} \times \mathrm{AS})$. We used the product terms to test for interaction effects (Aiken and West 1991).
In constructing the product terms, the product of individual ( $z$-scored) standardized variables was used and the resulting product variables were not restandardized. Although HLM output provides only unstandardized beta weights, these values in fact correspond to standardized beta weights for all variables except the product terms (interactions) as all predictor and outcome variables were standardized prior to analysis.

Using this set of independent, group mean-centered variables, we evaluated the intraindividual impact of control and value appraisals on state emotional experiences (Hypothesis 1). A significant $\mathrm{C} \times \mathrm{V}$ interaction would also indicate that control and value combine multiplicatively in predicting emotional experiences (Hypothesis 2). The other three interaction terms allow us to further explore whether situational characteristics play a role in moderating appraisal/emotion relations. More specifically, significant interactions involving the AS dummy variable would demonstrate the moderating influence of achievement settings on relations between control and emotions $(\mathrm{C} \times \mathrm{AS})$, value and emotions $(\mathrm{V} \times \mathrm{AS})$, as well as the interaction effect of control and value on emotional experiences $(\mathrm{C} \times \mathrm{V} \times \mathrm{AS})$. To graphically illustrate significant interaction effects, the graph modelling function of HLM 6.04 was employed.

\section{Results}

Preliminary analyses

Table 1 presents the means, standard deviations, as well as within-subject correlations for our variables. Means and standard deviations are shown as averaged across all subjects and daily reports $(N=2,100)$. A mean of 0.31 on the "achievement situation" dummy variable $(0=$ nonachievement, 1 = achievement) revealed that participants were referring to learning and achievement-related activities in $31 \%$ of their reports. The mean for perceived control was 3.70 and for perceived value was 4.39 . Concerning the emotion measures, participants scored highest on enjoyment $(M=3.51)$, followed by contentment $(M=3.23)$ and pride $(M=1.90)$.

Within-subject correlations are shown in Table 1 and can be interpreted as indicating the extent to which, on average, two constructs co-occur during the same reporting occasion $(N=2,100)$. For calculating the within-subject correlations, we first removed person differences (between-subject variance) by $z$-standardizing $(M=0.00, \mathrm{SD}=1.00)$ all variables separately for each participant (see Hox 2002; Raudenbush and Bryk 2002). The negative correlation between achievement situation and control (-.32) and positive correlation between achievement situation and 
Table 1 Descriptive statistics and within subject correlations

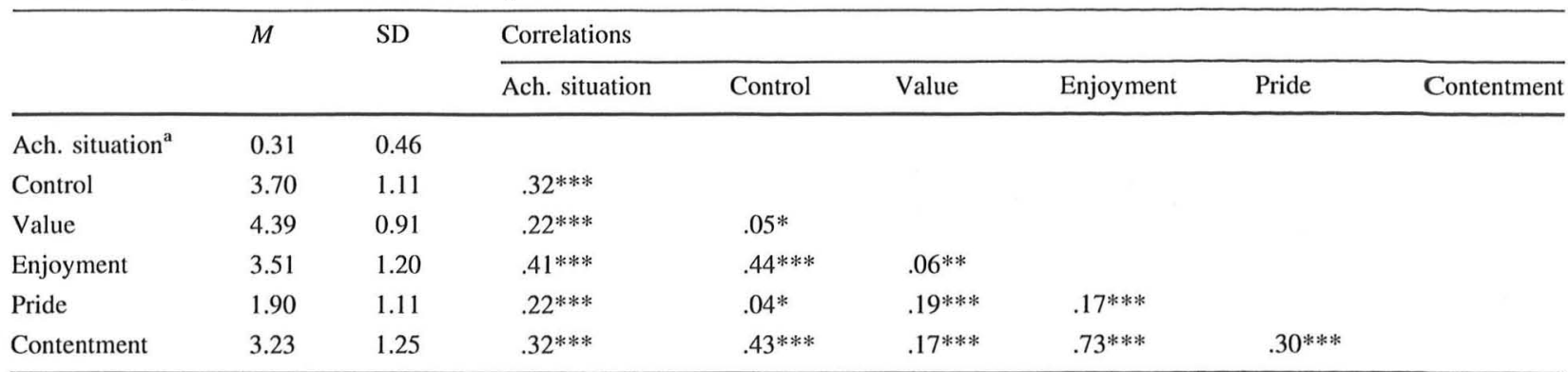

Note: The response format for emotions, control, and value consisted of a 5 point Likert scale ranging from 1 to 5 . Within subject correlations (N 2,100) are shown

$* p<.05 ; * * p<.01 ; * * * p<.001$

a Achievement situations ( 0 non achievement, 1 achievement)

value (.22) indicate that participants experienced less control but higher value in situations related to learning and achievement. Further, the low correlation between control and value (.05) indicates that both constructs seem to occur rather independently within persons. This finding is important because small correlations between control, value, and achievement situation suggest that multicollinearity is not a concern in our main analyses in which these variables are evaluated simultaneously. Finally, the preliminary within-subject correlations showed a relatively strong relationship between enjoyment and contentment (.73) while the relations between enjoyment and pride (.17) and contentment and pride (.30) were relatively weak.

In a next step, intraclass correlations were calculated in which the proportions of variance within persons (Level 1 variance; $\sigma^{2}$ ) relative to the total variance (Levels 1 and 2 variance; $\sigma^{2}+\tau_{00}$ ) was evaluated for the emotion, control, value, and achievement situation variables. Table 2 presents the results of the multilevel analysis on variance components at Level 1 (all reports of all subjects) and Level 2 (person aggregated values); an analysis equivalent to a one-way ANOVA with random effects (Raudenbush and Bryk 2002). The analysis of the Level 2 random effects shows that the number of situations related to learning and achievement, the levels of perceived control and value, as well as the levels of positive emotional experiences differed significantly across participants (each $p<.001$ ). Intraclass correlations were relatively weak and ranged from .08 to .29 .

\section{Main analyses}

The multilevel regression findings are presented in Table 3 . The three models assessed show the effects of control and value as appraisal antecedents on the emotions of enjoyment, pride, and contentment. Level 1 and Level 2 residual variances are also presented for each analytical model.

The achievement situation variable had a negative effect on enjoyment $(\beta=-.33 ; p<.001$; Enjoyment Model) indicating that participants reported lower levels of enjoyment in achievement vs. non-achievement settings. In addition, control and value had significant positive effects on enjoyment $(\beta=.35 / .15$ for control/value; $p<.001)$. These main effects on enjoyment were further qualified by a control $\times$ value interaction $(\beta=.06 ; p<.01)$. As presented in Fig. 1, the relation between control and enjoyment was stronger in situations of high value.

The achievement situation variable positively predicted feelings of pride $(\beta=.24 ; p<.001$, Pride Model) such

Table 2 Multilevel analysis of Level 1 and Level 2 random effects

\begin{tabular}{|c|c|c|c|c|c|}
\hline & \multicolumn{4}{|l|}{ Level 2 effect $u_{0 i}$} & \multirow{2}{*}{$\begin{array}{l}\text { Level } 1 \text { effect } r_{\mathrm{ij}} \\
\text { Variance within } \\
\text { students }\left(\sigma^{2}\right)\end{array}$} \\
\hline & $\begin{array}{l}\text { Variance between } \\
\text { students }\left(\tau_{00}\right)\end{array}$ & $d f$ & $\chi^{2}$ & $p$ & \\
\hline Ach. situation & .10 & 49 & 265.26 & $<.001$ & .90 \\
\hline Control & .29 & 49 & 846.86 & $<.001$ & .71 \\
\hline Value & .08 & 49 & 223.49 & $<.001$ & .92 \\
\hline Enjoyment & .09 & 49 & 243.82 & $<.001$ & .91 \\
\hline Pride & .21 & 49 & 581.78 & $<.001$ & .79 \\
\hline Contentment & .13 & 49 & 352.29 & $<.001$ & .87 \\
\hline
\end{tabular}

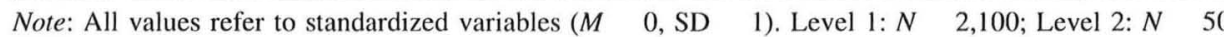


Table 3 Multilevel analysis on the antecedents of state emotions

\begin{tabular}{|c|c|c|c|c|c|c|}
\hline & \multicolumn{2}{|c|}{ Enjoyment } & \multicolumn{2}{|l|}{ Pride } & \multicolumn{2}{|c|}{ Contentment } \\
\hline & $b$ & $\mathrm{SE}$ & $b$ & SE & $b$ & SE \\
\hline Intercept & .00 & .05 & .04 & .07 & .00 & .06 \\
\hline Ach. situation $(A S)^{a}$ & $.33 * * *$ & .02 & $.24 * * *$ & .02 & $.25 * * *$ & .02 \\
\hline Control (C) & $.35 * * *$ & .02 & $.16^{* * * *}$ & .02 & $.34 * * *$ & .02 \\
\hline Value (V) & $.15 * * *$ & .02 & $.20 * * *$ & .02 & $.25 * * *$ & .02 \\
\hline \multicolumn{7}{|l|}{ Interactions } \\
\hline $\mathrm{C} \times \mathrm{V}$ & $.06 * *$ & .02 & $.06^{* *}$ & .02 & $.09 * * *$ & .02 \\
\hline $\mathrm{C} \times \mathrm{AS}$ & .03 & .02 & .00 & .02 & .03 & .02 \\
\hline $\mathrm{V} \times \mathrm{AS}$ & .01 & .03 & .05 & .03 & .00 & .03 \\
\hline $\mathrm{C} \times \mathrm{V} \times \mathrm{AS}$ & .01 & .02 & .00 & .02 & .02 & .03 \\
\hline \multicolumn{7}{|l|}{ Residual variance } \\
\hline Level 2 & .10 & & .22 & & .14 & \\
\hline Level 1 & .67 & & .65 & & .66 & \\
\hline
\end{tabular}

Note: All outcome and predictor variables were standardized $\left(\begin{array}{ll}M & 0\end{array}\right.$ $S D$ 1) across the entire sample. In constructing the product term, the product of individual ( $z$, scored) standardized variables was used. The product terms were not restandardized. All independent variables were group mean centered, that is, for each individual on his or her mean

$* p<.05 ; * * p<.01 ; * * * p<.001$

a Achievement situations; higher values indicate situations related to learning/achievement

that participants reported greater pride in situations involving learning and achievement than in other settings. Control and value also showed significant positive effects on pride $(\beta=.16 / .20$ for control/value; $p<.001)$. In addition, the control $\times$ value interaction was significant for feelings of pride $(\beta=.06 ; p<.01)$. Similar to the previous interaction effect, the relation between control and pride was stronger in situations of high value (see Fig. 1).

With respect to contentment, the achievement situation variable had a negative effect $(\beta=-.25 ; p<.001$, Contentment Model) indicating that participants were less content in achievement settings relative to non-achievement situations. Control and value had significant positive effects on contentment $(\beta=.34 / .25$ for control/value; $p<.001)$. These main effects on contentment were further qualified by a control $\times$ value interaction $(\beta=.09 ; p<.001)$. Once again, the relation between control and contentment was stronger in situations of high value (see Fig. 1).

The two- and three-way interactions involving achievement situations were not significant for any of the three emotions assessed $(p>.05)$. That is, the independent and combined effects of control and value on emotions were not moderated by the achievement-oriented nature of a given situation.

\section{Discussion and implications}

The present study explored the relations between positive emotions (enjoyment, pride, contentment) and cognitive appraisal antecedents (perceptions of control, value). Our study also evaluated both the independent as well as interactive effects of control and value appraisals on emotions as hypothesized in both classical and more recent appraisal theories of emotion. Our analyses further investigated the extent to which appraisal/emotion relations differed as a function of specific characteristics of the situations encountered, namely the achievement as opposed non-achievement nature of a given domain. In addressing our research questions, an experience sampling method consistent with recent research was employed (Nezlek et al. 2008; Tong et al. 2007) to improve upon the ecological validity of previous laboratory-based methods (e.g., retrospective recall, hypothetical vignettes). Finally, a multilevel approach was adopted (HLM; Raudenbush and Bryk 2002) so as to provide an optimally elaborate and idiographic analysis detailed selfreport data obtained (see Lamiell 1998).

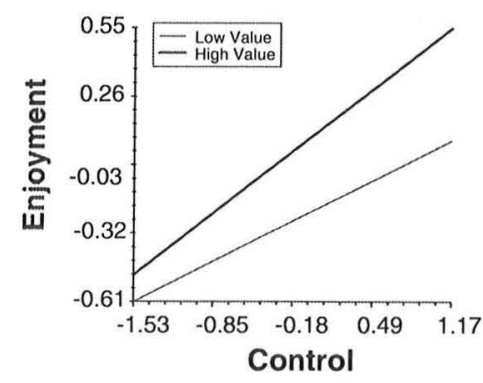

Fig. 1 Illustration of significant interaction terms found in Table 3. Note: These figures were created using the graph modelling function (equation graphing) of multilevel software HLM 6.04 (Hierarchical Linear Modeling; Raudenbush et al. 2007; Raudenbush and Bryk 2002). The specifications were as follows: $x$ focus on Level 1 : control; $z$ focus on Level 1: value; interaction: control $x$ value.
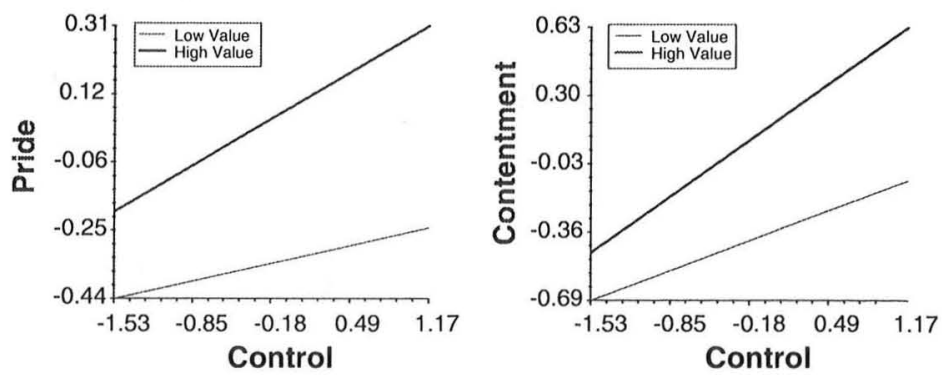

Concerning the $x$ axis range, the 5 th 95 th percentiles of perceived control are depicted to exclude outliers. With respect to the $z$ focus, the value variable was dichotomized based on the averaged lower and upper quartiles. Standardized $z$ scores $\left(\begin{array}{lll}M & 0, S D & 1\end{array}\right)$ are shown on both the $x$ axis (levels of control) and on the $y$ axis (levels of enjoyment, pride, and contentment) 
Intraindividual variability in appraisals and emotions

A set of intriguing findings from our preliminary analyses were the noticeably low intraclass correlations found for appraisals and positive emotions (.29 for control, .08 for value; ranging from .09 to .21 for emotions). These results suggest that differences in mean levels of both appraisals and discrete positive emotions between individuals were relatively minor compared to the differences within individuals. These findings are consistent with those of Nezlek et al. (2008) in which intraindividual fluctuations in appraisals (e.g., perceived threat, loss) and positive emotions (joy, love) within a given day were much stronger than that observed between days, or the variability observed between individuals. Thus, the results of our study provide further empirical support for the assumption that both cognitive appraisals as well as positive emotions demonstrate a high degree of within-person variability. Consequently, the question arises as to whether or not it is meaningful to assess individuals' appraisals and their discrete positive emotions as mean levels aggregated over time (cf., Burke et al. 1999; Luedtke et al. 2006). Our data suggests that by evaluating aggregate levels of strongly fluctuating appraisals and discrete emotions within persons, a considerable degree of temporal variation in these constructs within individuals is not accounted for in the findings observed.

\section{Control/value main effects (Hypothesis 1)}

The first research question was based on the assumptions of classical appraisal theories (e.g., Scherer et al. 2001), and addressed whether cognitive appraisals of control and value were related to discrete positive emotional experiences as assessed in everyday life. In line with our hypothesis, the relations between perceived control and enjoyment, pride, and contentment were all positive in nature. These results provide empirical support for perceived control as a critical antecedent of positive emotions in everyday life. This finding further implies that enhancing perceptions of personal control may be an effective way in which positive emotional experiences can be fostered (cf., positive psychology; Seligman and Csikszentmihalyi 2000). For example, perceived control may be enhanced through explicit training in problem-oriented coping strategies (see Rost and Schermer 1987; Skinner et al. 2003; Zeidner and Endler 1996). Our findings are also consistent with the research literature on a motivational intervention referred to as "attributional retraining" (AR; see Foersterling 1985; 1986, for reviews) which aims to enhance perceptions of personal control by promoting controllable explanations for failure events (see Hall et al. 2006; Hall et al. 2007; Perry et al. 2007).
Also consistent with our hypothesis, all positive emotions were positively related to perceptions of value. Our study is, to our knowledge, the first to provide empirical findings in support of the impact of perceived value on positive emotions in everyday life. The results of the present research suggest that people tended to be more joyful, proud, and content while engaging in activities that they considered more important. Thus, our findings suggest that efforts to underscore the personal relevance of adaptive activities could serve to enhance positive emotions surrounding these experiences. Concerning the achievement context, this result is in line with empirical evidence from educational psychology research suggesting that greater emphasis by teachers on the personal relevance of learning material (e.g., using tasks with real-world applications, or "authentic" tasks; Bergin 1999; Hiebert 1994) contributes significantly to more positive emotional experiences in their students (Ames 1992; Fraser and Walker 2005). With respect to non-achievement contexts, our results suggest that, for example, highlighting the shortand long-term physical and psychological benefits of exercising or eating healthy food (i.e., enhancing the value) could enhance positive emotions related to these activities that, in turn, motivate continued engagement in such healthy behaviors.

\section{Control/value interaction effects (Hypothesis 2)}

In analyzing our second research hypothesis, we investigated whether control and value appraisals combined to predict positive emotional experiences in everyday settings in a multiplicative manner. In other words, the interactive configuration of control and value appraisals was assumed to be of added benefit with respect to positive emotional experiences. To our knowledge, this assumption has not yet been empirically addressed in the context of real-life experiences. Indeed, this interaction (control $\times$ value) was observed in the present study, with one possible explanation being that perceived control and positive emotions were stronger in situations of high subjective value. Alternatively, this interaction could be interpreted as suggesting that the relations between value and positive emotions were stronger in situations appraised as affording greater personal control. For example, students' perceptions of control may more strongly affect their emotions in a more interesting class (high value) as compared to a more mundane class (low value). It is also plausible that students' perceptions of value may have a larger impact on emotions in subjects where they feel competent (high control) as compared to subjects in which their subjective competence beliefs are low (low control).

It is important to note that the appraisal interaction term (control $\times$ value) predicted positive emotions while 
controlling for its constituent main effects. That is, control and value appraisals were found to have an added multiplicative impact on positive emotions consistent with the afore-mentioned assumptions in classical appraisal theories (e.g., Roseman et al. 1990, 1996; Smith and Ellsworth 1985). Our results suggest that the link between appraisals and emotional experiences can be understood both in terms of the unique contributions of specific appraisals as well as the combined effect of appraisal configurations. Moreover, our findings further imply that whereas positive emotions may be enhanced by modifying either perceptions of personal control or value-related cognitions, the most efficacious investment of intervention-related resources would involve programs that promote both appraisal constructs.

For example, positive emotional experiences may be optimally benefitted by incorporating effective writingbased programs focusing on personal values (e.g., Cohen et al. 2006) into existing attributional retraining programs that encourage greater perceived control (e.g., Hall et al. 2007). Alternatively, these results suggest that the effectiveness of control-enhancing programs may be more readily observed in situations of greater personal value to participants (e.g., in elective vs. required university courses), and similarly, that value-oriented programs may be most effective in settings affording greater personal control (e.g., university vs. high-school classes).

\section{Control/value and achievement situations}

Based on the assumptions of Pekrun's (2006) theory of achievement emotions and classical appraisal theories, our study explored the potential impact of the achievementoriented nature of a given situation on control/value and positive emotion relations. As outlined in Table 3, the relations between perceptions of control or value and positive emotions did not differ as a function of whether or not a given activity was achievement-related. Moreover, neither the independent effects nor the combined, interactive effects of control and value on emotions were moderated by achievement settings. As such, these findings highlight the importance of control and value appraisals as critical antecedents of positive emotional experiences both within and outside achievement settings. Furthermore, these results suggest that interventions aimed at fostering positive emotional experiences by enhancing control and value-related cognitions are likely to be effective when administered both in achievement-oriented settings (e.g., school classroom, workplace) as well as non-achievement domains (e.g., leisure activities, daily routines).

Nevertheless, an additional study finding beyond the scope of our research questions indicated that even when controlling for the main and interaction effects of appraisals on emotions, the achievement-related nature of a given situation did have a significant impact on emotional experiences. More specifically, in situations related to learning and achievement, as compared to other settings, participants experienced not only lower levels of enjoyment and contentment, but also higher levels of pride. One explanation for this finding may be that achievement-related settings are typically evaluative in nature, and are thus more likely to threaten perceptions of self-worth (e.g., Covington 1992). Consequently, such threats to self-worth typically result in decreased enjoyment and contentment. At the same time, however, evaluative exercises can foster outcome-based feelings of pride should success be achieved.

Thus, despite the non-significant two- and three-way interactions between the achievement situation measure and cognitive appraisals, the significant and interpretable main effects of this variable on emotional experiences nonetheless provides evidence in support of the overall predictive validity of our achievement situation measure. In other words, these results suggest that the distinction between situations perceived as involving learning or achievement, as opposed to those that do not (e.g., exercising, shopping), is meaningful in nature. As a corollary, these findings lend support for interpreting the non-significant effect of the situational characteristics on appraisal/ emotion relations not as the result of an invalid measure but as evidence of the limited utility of the distinction between achievement vs. non-achievement settings as predictive of differential relations between perceptions of control and value and subsequent emotional experiences.

\section{Directions for future research}

An important avenue for further research on the appraisal/ emotion relations involves the examination of other positive but also negative emotions not investigated in the present study, such as enthusiasm and relief, as well as anger, boredom, shame, guilt, or disappointment. For example, boredom is often described as epidemic in modern societies (e.g., Spacks 1995) yet empirical knowledge concerning antecedent factors is sorely lacking (see Goetz et al. 2006, for more on value-related antecedents of boredom). Further research on cognitive appraisals and boredom as experienced in everyday situations may contribute to the development of interventions aimed at reducing boredom and the detrimental consequences thereof (see Pekrun et al. 2009).

Second, future studies might also explore the relations between state emotional experiences (i.e., in vivo assessments) and additional appraisal dimensions such as goal congruency, expectedness and probability, as well as selfvs. other-causation (see Roseman 2001; Scherer 2001). It is assumed that by evaluating alternate appraisal constructs alongside those assessed in the present study that the 
relative importance of control and value as emotion antecedents can be more accurately assessed, and that a core of appraisal constructs relevant to emotional experience may be identified so as to best inform future interventions. Third, future research in which alternative moderating factors with respect to appraisal/emotion relations are explored, such as cultural context (e.g., China vs. Western European countries; cf., Frenzel et al. 2007) or age (e.g., younger vs. older adults), may also provide critical information on the generalizeability of the present findings across different demographic groups.

A fourth topic for future research concerns the direction of appraisal/emotion relations, due to the possibility of reverse causality in which emotions predict cognitive appraisals (cf., Marsh and Ayotte 2003). For example, a student could later attribute initial feelings of pride in a given context to high competence in that domain (see Bandura 1997; for a theoretical perspective on reciprocal relations between perceived competence and emotions, see Pekrun 2006). Research investigating the effects of changes in cognitive appraisals (e.g., interventions fostering perceived control) on everyday life emotional experiences, or the effects of changes in positive emotions (e.g., by adopting an enthusiastic teaching style; Frenzel et al. 2009) on real-life assessments of perceived control is warranted. Finally, further research on intervention programs intended to promote perceptions of control (e.g., Hall et al. 2006, 2007), value (e.g., Cohen et al. 2006), or both (see control/ value interaction effects) is needed in order to encourage cognitive appraisals that optimally contribute to emotional well-being, and in turn, promote adjustment and performance in everyday life.

\section{References}

Aiken, L. S., \& West, S. G. (1991). Multiple regression: Testing and interpreting interactions. Newbury Park, CA: Sage.

Alloy, L. B., \& Abramson, L. Y. (1979). Judgment of contingency in depressed and nondepressed students: Sadder but wiser? Journal of Experimental Psychology: General, 108, 441485.

Alloy, L. B., \& Clements, C. M. (1992). Illusion of control: Invulnerability to negative affect and depressive symptoms after laboratory and natural stressors. Journal of Abnormal Psychology, 101,234245 .

Ames, C. (1992). Classrooms: Goals, structures, and student motiva tion. Journal of Educational Psychology, 84, 261271.

Arnold, M. B. (1960). Emotion and personality. New York: Columbia University Press.

Atkinson, J. W. (1964). An introduction to motivation. Princeton, NJ: Van Nostrand.

Bandura, A. (1977). Self efficacy: Toward a unifying theory of behavioral change. Psychological Review, 84, 191215.

Bandura, A. (1989). Human agency in social cognitive theory. American Psychologist, 44, 11751184.
Bandura, A. (1997). Self efficacy. The experience of control. New York: W. H. Freeman and Company.

Bergin, D. A. (1999). Influences on classroom interest. Educational Psychologist, 34, 8798.

Burger, J. M. (1989). Negative reactions to increases in perceived personal control. Journal of Personality and Social Psychology, 56, 246256.

Burke, M. J., Finkelstein, L. M., \& Dusig, M. S. (1999). On average deviation indices for estimating interrater agreement. Organiza tional Research Methods, 2(1), 4968.

Clore, G. L. (1994). Why emotions require cognition. In P. Ekman \& R. J. Davidson (Eds.), The nature of emotion (pp. 181 191). New York: Oxford University Press.

Cohen, G. L., Garcia, J., Apfel, N., \& Master, A. (2006). Reducing the racial achievement gap: A social psychological intervention. Science, 313, 13071310.

Covington, M. V. (1992). Making the grade: A self worth perspective on motivation and school reform. New York, NY: Cambridge University Press.

Csikszentmihalyi, M., \& Larson, R. (1987). Validity and reliability of the experience sampling method. Journal of Nervous and Mental Diseases, 9, 526536.

Foersterling, F. (1985). Attributional retraining: A review. Psycho logical Bulletin, 98, 495512.

Foersterling, F. (1986). Attributional conceptions in clinical psychol ogy. American Psychologist, 41, 275285.

Fraser, B. J., \& Walker, S. L. (2005). Development and validation of an instrument for assessing distance education learning environ ments in higher education: The distance education learning environments survey (DELES). Learning Environments Research, 8, 289308.

Fredrickson, B. L. (2001). The role of positive emotions in positive psychology. American Psychologist, 56(3), 218226.

Frenzel, A. C., Goetz, T., Lüdtke, O., Pekrun, R., \& Sutton, R. E. (2009). Emotional transmission in the classroom: Exploring the relationship between teacher and student enjoyment. Journal of Educational Psychology, 101(3), 705716.

Frenzel, A. C., Pekrun, R., \& Goetz, T. (2007a). Girls and mathematics A "hopeless" issue? A control value approach to gender differences in emotions towards mathematics. Euro pean Journal of Psychology of Education, 22(4), 497514.

Frenzel, A. C., Thrash, T. M., Pekrun, R., \& Goetz, T. (2007b). Achievement Emotions in Germany and China: A cross cultural validation of the academic emotions questionnaire mathematics (AEQ M). Journal of Cross Cultural Psychology, 38(3), 302309.

Goetz, T. (2004). Emotionales Erleben und selbstreguliertes Lernen bei Schulern im Fach Mathematik [Students' emotions and self regulated learning in mathematics]. Munich: Utz.

Goetz, T., Frenzel, C. A., Hall, N. C., \& Pekrun, R. (2008). Antecedents of academic emotions: Testing the internal/external frame of reference model for academic enjoyment. Contempo rary Educational Psychology, 33, 933.

Goetz, T., Frenzel, C. A., Pekrun, R., Hall, N. C., \& Lüdtke, O. (2007a). Between and within domain relations of students' academic emotions. Journal of Educational Psychology, 99(4), 715733.

Goetz, T., Pekrun, R., Hall, N. C., \& Haag, L. (2006). Academic emotions from a social cognitive perspective: Antecedents and domain specificity of students' affect in the context of Latin instruction. British Journal of Educational Psychology, 76(2), 289308.

Goetz, T., Preckel, F., Pekrun, R., \& Hall, N. C. (2007b). Emotional experiences during test taking: Does cognitive ability make a difference? Learning and Individual Differences, 17, 316.

Hall, N. C., Perry, R. P., Chipperfield, J. G., Clifton, R. A., \& Haynes, T. L. (2006). Enhancing primary and secondary control in 
achievement settings through writing based attributional retrain ing. Journal of Social and Clinical Psychology, 25, 361391.

Hall, N. C., Perry, R. P., Goetz, T., Ruthig, J. C., Stupnisky, R. H., \& Newall, N. E. (2007). Attributional retraining and elaborative learning: Improving academic development through writing based interventions. Learning and Individual Differences, 17(3), 280290.

Heckhausen, H. (1977). Achievement motivation and its constructs: A cognitive model. Motivation and Emotion, 1, 283329.

Hektner, J. M., Schmidt, J. A., \& Csikszentmihalyi, M. (2007). Experience sampling method: Measuring the quality of everyday life. Thousand Oaks, CA: Sage.

Henson, H. N., \& Chang, E. C. (1998). Locus of control and the fundamental dimensions of moods. Psychological Reports, 82, 13351338.

Hiebert, E. H. (1994). Becoming literate through authentic tasks: Evidence and adaptations. In H. Singer, R. B. Ruddell, \& M. R. Ruddell (Eds.), Theoretical models and processes of reading. Newark, DE: International Reading Association.

Hoffart, A., \& Martisen, E. W. (1990). Agoraphobia, depression, mental health locus of control, and attributional styles. Cognitive Therapy and Research, 14, 343351.

Hox, J. J. (2002). Multilevel analysis: Techniques and applications. Mahwah, NJ: Lawrence Erlbaum Associates.

Lamiell, J. T. (1998). 'Nomothetic' and 'idiographic': Contrasting Windelband's understanding with contemporary usage. Theory \& Psychology, 8(1), 2338.

Lazarus, R. S. (1991). Emotion and adaption. New York: Oxford University Press.

Lazarus, R. S. (1995). Vexing research problems inherent in cognitive mediational theories of emotion and some solutions. Psychological Inquiry, 6, 183196.

Lefcourt, H. M. (Ed.). (1983). Research with the locus of control construct: Vol 2. Developments and social problems. San Diego: Academic Press.

Levenson, H. (1973). Perceived parental antecedents of internal, powerful others, and chance locus of control orientations. Developmental Psychology, 9, 260265.

Long, G. (1991). Epictetus: The Enchiridion (chapter 5). Amherst, NY: Prometheus Books.

Luedtke, O., Trautwein, U., Kunter, M., \& Baumert, J. (2006). Reliability and agreement of student ratings of the classroom environment: A reanalysis of TIMSS data. Learning Environ ments Research, 9, 215230

Marsh, H. W., \& Ayotte, V. (2003). Do multiple dimensions of self concept become more differentiated with age? The differential distinctiveness hypothesis. Journal of Educational Psychology, 94(4), 687706.

Marsh, H. W., \& Rowe, K. J. (1996). The negative effects of school average ability on academic self concept: An application of multilevel modelling. Australian Journal of Education, 40, 6587.

Nezlek, J. B., Vansteelandt, K., Mechelen, I. V., \& Kuppens, P. (2008). Appraisal emotion relationships in daily life. Emotion, $8(1), 145150$.

Pekrun, R. (2000). A social cognitive, control value theory of achievement emotions. In J. Heckhausen (Ed.), Motivational psychology of human development (pp. 143 163). Oxford: Elsevier.

Pekrun, R. (2006). The control value theory of achievement emo tions: Assumptions, corollaries, and implications for educational research and practice. Educational Psychology Review, 18, 315 341.

Pekrun, R., Goetz, T., Daniels, L. M., Stupnisky, R. H., \& Perry, R. P. (2009). Boredom in achievement settings: Exploring appraisal antecedents and performance outcomes of a neglected emotion. Journal of Educational Psychology (in press).
Pekrun, R., Goetz, T., Titz, W., \& Perry, R. P. (2002a). Academic emotions in students' self regulated learning and achievement: A program of qualitative and quantitative research. Educational Psychologist, 37(2), 91105.

Pekrun, R., Goetz, T., Titz, W., \& Perry, R. P. (2002b). Positive emotions in education. In E. Frydenberg (Ed.), Beyond coping. Meeting goals, visions, and challenges (pp. 149 174). Oxford, UK: Elsevier.

Perry, R. P., Hall, N. C., \& Ruthig, J. C. (2007). Perceived (academic) control and scholastic attainment in college students. In R. P. Perry \& J. Smart (Eds.), The scholarship of teaching and learning in higher education: An evidence based perspective (pp. 477 551). New York: Springer.

Raudenbush, S. W., \& Bryk, A. S. (2002). Hierarchical linear models. Applications and data analysis methods (2nd ed.). Thousand oaks: Sage.

Raudenbush, S. W., Bryk, A., \& Congdon, R. (2007). HLM 6.04. Hierarchical linear and nonlinear modeling. Lincolnwood: Scientific Software International.

Roseman, I. J. (2001). A model of appraisal in the emotion system: Integrating theory, research and applications. In K. R. Scherer, A. Schorr, \& T. Johnstone (Eds.), Appraisal processes in emotion (pp. 68 91). Oxford, UK: Oxford University Press.

Roseman, I. J., Antoniou, A. A., \& Jose, P. E. (1996). Appraisal determinants of emotions: Constructing a more accurate and comprehensive theory. Cognition and Emotion, 10, 241277.

Roseman, I. J., \& Smith, C. A. (2001). Appraisal theory: Overview, assumptions, varieties, controversies. In K. R. Scherer, A. Schorr, \& T. Johnstone (Eds.), Appraisal processes in emotion (pp. 3 19). Oxford, UK: Oxford University Press.

Roseman, I. J., Spindel, M. S., \& Jose, P. E. (1990). Appraisals of emotion eliciting events: Testing a theory of discrete emotions. Journal of Personality and Social Psychology, 59, 899915.

Rost, D. H., \& Schermer, F. J. (1987). Emotion and cognition in coping with test anxiety. Communication and Cognition, 20, 225244 .

Rotter, J. B. (1966). Generalized expectancies for internal versus external control of reinforcement. Psychological Monographs, 80(1) (Whole No. 609).

Scherer, K. R. (1984). On the nature and function of emotion: A component process approach. In K. R. Scherer \& P. Ekman (Eds.), Approaches to emotion (pp. 293 317). Hillsdale, NJ: Erlbaum.

Scherer, K. R. (Ed.). (1988). Facets of emotion. Recent research. Hillsdale, NJ: Erlbaum.

Scherer, K. R. (2001). Appraisal considered as a process of multilevel sequential checking. In K. R. Scherer, A. Schorr, \& T. Johnstone (Eds.), Appraisal processes in emotion (pp. 92 120). Oxford, UK: Oxford University Press.

Scherer, K. R., Schorr, A., \& Johnstone, T. (Eds.). (2001). Appraisal processes in emotion. Oxford, UK: Oxford University Press.

Scherer, K. R., Wranik, T., Sangsue, J., Tran, V., \& Scherer, U. (2004). Emotions in everyday life: Probability of risk factors, appraisal and reaction patterns. Social Science Information, 43, 499570.

Seligman, M. E. P., \& Csikszentmihalyi, M. (2000). Positive psychology: An introduction. American Psychologist, 55(1), 5 14.

Skinner, E. A. (1985). Action, control judgments, and the structure of control experience. Psychological Review, 92, 3958.

Skinner, E. A. (1996). A guide to constructs of control. Journal of Personality and Social Psychology, 71(3), 549570.

Skinner, E. A., Edge, K., Altman, J., \& Sherwood, H. (2003). Searching for the structure of coping: A review and critique of category systems for classifying ways of coping. Psychological Bulletin, 129(2), 216269. 
Smith, C. A., \& Ellsworth, P. C. (1985). Patterns of cognitive appraisal in emotion. Journal of Personality and Social Psychology, 48, 813838.

Smith, C. A., Haynes, K. N., Lazarus, R. S., \& Pope, L. K. (1993). In search of the "hot" cognitions: Attributions, appraisals, and their relations to emotion. Journal of Personality and Social Psychol ogy, 65, 916929

Spacks, P. M. (1995). Boredom: The literary history of a state of mind. Chicago, IL: University of Chicago Press.

Stumpf, C. (1899). Über den Begriff der Gemüthsbewegung [On the concept of emotion]. Zeitschrift fur Psychologie und Physiologie der Sinnesorgane, 44, 149.

Tong, E. M. W., Bishop, G. D., Enkelmann, H. C., Why, Y. P., Diong, S. M., Khader, M., et al. (2005). The use of ecological momentary assessment to test appraisal theories of emotion. Emotion, 5(4), 508512.

Tong, E. M. W., Bishop, G. D., Enkelmann, H. C., Why, Y. P., Diong, S. M., Khader, M., et al. (2007). Emotion and appraisal: A study using ecological momentary assessment. Cognition and Emo tion, 2l(7), 13611381.

Wanous, J. P., Reichers, A. E., \& Hudy, M. J. (1997). Overall job satisfaction: How good are single item measures? Journal of Applied Psychology, 82(2), 247252.

Weiner, B. (1985). An attributional theory of achievement motivation and emotion. Psychological Review, 92(4), 548573.

Zeidner, M., \& Endler, N. (Eds.). (1996). Handbook of coping. New York: Wiley. 